\title{
Las representaciones sociales del medio ambiente: el papel de la fotografia
}

\author{
Angela Castrechini, Enric Pol y Tomeu Vidal \\ Universitat de Barcelona
}

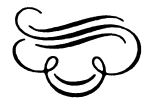

\section{Resumen}

Este estudio se centra en el papel de la fotografía en la construcción de la representación social (RS) del medio ambiente. En el contexto de una investigación sobre la RS de los problemas ambientales en la prensa (Castrechini y Pol, 2006), se ha encontrado que un elemento clave de esta representación social está formado por los elementos gráficos. En este trabajo se presentan los resultados del análisis de las referencias fotográficas utilizadas para ilustrar y/o acompañar tales noticias.

Se analizó una muestra de 266 fotografías procedentes de dos diarios: La Vanguardia y El País en su edición barcelonesa. El período de estudio comprendió desde el año 1992 hasta el 2002. El procedimiento consiste en categorizar los diferentes temas contenidos en las fotografías. Para su categorización no se parte de un sistema de categorías establecido a priori, sino que éste se ha ido construyendo a partir de la información proporcionada por el propio material analizado (Strauss y Corbin, 1990). Se obtienen cuatro categorías principales: actores sociales, paisajes, afectación del medio ambiente y acciones sociales.

Destaca una presencia mayoritaria de figuras políticas que puede reflejar el uso (y abuso) interesado de la prensa de algunas fuentes informativas y/o la hegemonía de una fuente por encima de las otras. Por otra parte, es de resaltar la alta presencia de fotografías de escenario urbanos. Ello puede estar indicando un cambio en la representación social del medio ambiente, históricamente referido al paisaje natural y reflejo de la asociación tradicional entre naturaleza y conservacionismo. Las pruebas estadísticas realizadas muestran la existencia de diferencias significativas en cuanto al tipo de tema contenido en las fotografías a lo largo del período analizado.

Palabras clave: Psicología ambiental, representaciones sociales, noticias ambientales, análisis de medios de comunicación, análisis de fotografías.

\section{Social representation of environment: The role of photographs}

\begin{abstract}
The objective of this paper is to examine the role that photography plays in social representation of environment. In the context of a broader research on Social Representation (SR) of environmental problems in press (Castrechini and Pol, 2006), it was found that graphic elements of news are a key component of such a social representation. This paper presents the results of analyzing the photographic references used to illustrate andlor support such news.

A sample of 266 photographs was analyzed, which corresponded to two national newspapers: La Vanguardia and El País (Barcelona's edition). The period of study was from 1992 to 2002. The analysis included categorizing the issues contained in a sample of photographs from newspaper news. For this analysis, a categorical system was built based on the information provided by the material (Strauss and Corbin, 1990). Four main categories of analysis were obtained: Social actors, landscapes, environmental problems and social actions.

Results show a predominance of politicians' photos, which may reflect the use (and abuse) of some information sources by the media orland the hegemony of one source above the others. Furthermore, the high number of urban landscape photos could indicate a change in the social representation of environment, which has been historically associated to natural landscape due to the traditional association nature-conservation. Statistical tests show significant differences with respect to the kind of content in the photos along the period of analysis.
\end{abstract}

Keywords: Environmental Psychology, social representations, environmental news, mass media análisis, photograph analysis.

Correspondencia con los autores: Angela Castrechini. Departament de Psicología Social. Facultad de Psicología. Universidad de Barcelona. Pg. de la Vall d'Ebron, 171. 08035 Barcelona. Email: acastrechini@ub.edu 
Muchos de los problemas medioambientales que preocupan a la mayoría de la gente se han vuelto cada vez más abstractos y difíciles de experimentar de manera directa. Los problemas globales (tales como el agujero en la capa de ozono, la lluvia ácida o el cambio climático) no pueden ser percibidos directamente por las personas. Si bien las personas no expertas pueden percibir su presencia a través de ciertos indicadores (como por ejemplo, mayor incidencia de cáncer de piel, la pérdida de cultivos, o el deshielo de la Antártica), muchas de las manifestaciones directas de los problemas ambientales no son observadas ni sentidas directamente por los afectados. En lugar de la experiencia directa, la gente depende de la información, esencialmente de base científica, que les llega principalmente a través de los medios de comunicación social. Este estudio se centra en demostrar el papel de la fotografía en la representación social del medio ambiente.

Los temas ambientales, en términos generales, son conceptualizados como problemas durante el proceso de generación de las noticias ambientales. Los periodistas, las diversas fuentes de información, el equipo editorial de los diarios y el público, en general, intervienen en el proceso de generación de estas noticias. Todos ellos son considerados actores sociales que juegan diferentes roles y moldean la realidad social a través de la toma de decisiones acerca de lo que es y de lo que no es noticia. En este estudio nos centraremos en demostrar el papel de la fotografía en la representación social del medio ambiente. Se parte de un enfoque construccionista y el presente trabajo se basa en la Teoría de las Representaciones Sociales (TRS) de Moscovici para describir la construcción social que realizan los media de los temas medioambientales.

\section{Representaciones Sociales y Medios de Comunicación Social}

La TRS se ha mantenido por cerca de 30 años en el campo de la investigación de la Psicología Social, cuando otros enfoques han decaído inevitablemente con menor tiempo de vida. Si bien este es solo un dato fáctico, refleja no sólo el mantenimiento de un cuerpo investigativo relativamente estable (nótese la lista de investigadores como R. Farr, W. Doise, W. Wagner, G. Duveen en el contexto europeo), sino también la incorporación de nuevos investigadores provenientes de una amplia gama de contextos geográficos.

Como indica Moscovici, las Representaciones Sociales (RS) son "un conjunto de conceptos, afirmaciones y explicaciones en el marco de la vida cotidiana, originados en el curso de las comunicaciones interindividuales" (1981; p. 181). Con posterioridad, Moscovici, afirma: "la TRS es una teoría particular de las formas colectivas de pensamiento y creencia y de las comunicaciones producidas bajo la acción constrictiva de la sociedad" (1993; p. 161). Se establece así una cierta equivalencia entre las RS en las sociedades modernas con los sistemas de creencias y mitos existentes en sociedades tradicionales. Este autor afirma que pueden ser consideradas la versión contemporánea del sentido común. En la construcción de este "sentido común", los mass media juegan un papel clave, que se ve especialmente matizado y/o reforzado por los apoyos gráficos con los que se acompaña la información escrita.

Las fuentes de determinación de las representaciones sociales son muy variadas; sin embargo, los teóricos sobre el tema (Ibáñez, 1988) coinciden en agruparlas en tres tipos. En primer lugar, aquéllas que se encuentran en el conjunto de condiciones económicas, sociales, históricas que caracterizan a una sociedad determinada y en el sistema de creencias y de valores que circulan en su seno. En segundo lugar, aquellas fuentes que provienen de la propia dinámica de las representaciones sociales y de sus mecanismos internos de formación: objetivación y anclaje. Para finalizar, las representaciones sociales están determinadas por 
fuentes asociadas al conjunto de prácticas sociales que se encuentran relacionadas con las diversas modalidades de comunicación social.

En relación con este último punto, Ibáñez (1988) especifica, a su vez, tres tipos de modalidades: (i) comunicaciones provenientes de medios de alcance general (TV, radio y prensa); (ii) comunicaciones dirigidas a categorías sociales más específicas, como por ejemplo las revistas de divulgación científica; y (iii) la comunicación interpersonal, o conversaciones en las que participa toda persona durante el transcurso de un día cualquiera en su vida cotidiana. En opinión de Ibáñez "en estas conversaciones no solamente afloran RS sino que en ellas se constituyen literalmente las RS” (1988, p. 42).

La TRS básicamente propone que el conocimiento de los individuos se desarrolla durante y como resultado de los procesos sociales. El individuo no es concebido como un receptor pasivo de información cuyos procesos perceptivos son gobernados por fuerzas ambientales, sino que es concebido como un participante activo en su interacción con otros individuos durante los cuales se construye el conocimiento (Moscovici, 1997). Las representaciones no son creadas por los individuos en situaciones de aislamiento sino en el curso de la comunicación y la cooperación (Moscovici, 1984).

Para Wagner (1996), la RS es el conjunto de creencias, opiniones, símbolos, metáforas e imágenes construidas socialmente que juegan un rol vital en la construcción del entorno cotidiano e inmediato de la gente. Por tanto, las RS son elaboradas, re-pensadas, re-citadas y re-presentadas a través de la comunicación y de la interacción social en las actividades cotidianas. Desde la TRS se asume que las prácticas sociales reflejan y crean la RS a través de un tipo de dinámica dialógicacircular, esto es, una dinámica según la cual la RS guía el acto de comunicación, pero al mismo tiempo, es transformada por la comunicación misma.

En el proceso de transformación de las creencias cognitivas en normativas, no cabe duda de que Moscovici (2000) enfatiza el papel de la comunicación en la formación de las representaciones sociales. Aún más, destaca cómo los procesos de comunicación dan forma y transforman las representaciones compartidas.

\section{Representaciones Sociales y Medio Ambiente}

Llegados a este punto, surge el interrogante sobre las contribuciones de la TRS para estudiar el medio ambiente, así como el interés por recoger los autores que han estudiado las temáticas medioambientales desde el enfoque de las RS y la forma en que lo han abordado. Aún son pocos, aunque relevantes e icónicos, los trabajos que sobre el medio ambiente se han hecho desde la perspectiva de las RS. Este ámbito ha sido particularmente fértil en el contexto francés, en donde se observa un equipo investigador, encabezado por Denise Jodelet, en el que, desde hace tres décadas, se emplea esta teoría como pilar fundamental de los estudios sobre medio ambiente. Actualmente, las investigaciones se orientan sobre dos ejes: uno correspondiente a las representaciones socio-espaciales de la ciudad y el otro concerniente a las RS de los problemas medioambientales.

Uno de los referentes clásicos es el estudio realizado por Milgram y Jodelet (1976) que analizaba la relación entre las RS y la ciudad, estudiando las ciudades de Paris y Nueva York a través de la técnica de mapas cognitivos de Lynch. Posteriormente, estos autores continuaron desarrollando esta línea de investigación. Milgram publica en el año 1984, dentro de unos de los libros clásicos de RS, el capítulo titulado "Cities as social representations". Este estudio representa un claro ejemplo del uso de la TRS para el estudio del medio ambiente, específicamente, el medio urbano. 
Las investigaciones de Milgram y Jodelet constituyen los trabajos pioneros que establecieron el vínculo entre la TRS y el estudio del medio ambiente. A partir de entonces, aunque pocas han sido las investigaciones que se han sumado a esta tendencia, los contextos geográficos han sido muy variados. En ellos se analiza la representación de diferentes objetos vinculados al medio ambiente, desde la propia conceptualización del medio ambiente como noción abstracta (Jodelet, 1996), pasando a los contextos urbanos -ciudades, comunidades o urbanizaciones-(Bomfim y Pol, 2005; Jodelet, 1996) y naturales (Arruda, 1998; Castro, 2002; Castro y Lima, 2001) y de allí a la representación de los problemas ambientales de diversos tipos -locales a globales-(Castrechini, 1996; Castrechini y Pol, 2006; Gervais, 1994). Es de destacar que en la mayoría de los estudios subyace un enfoque socioconstruccionista en la aproximación de la RS.

Desde el punto de vista metodológico, las técnicas empleadas para recoger la RS abarcan desde el uso de mapas cognitivos y afectivos, vinculadas muchas veces a la realización de entrevistas individuales o grupales, a la utilización de fuentes de procedencias variadas, como en el caso del análisis de los medios de comunicación (TV y prensa) para disponer de documentos susceptibles de análisis. Aunque hay una ligera tendencia a emplear varias técnicas en un mismo estudio, resalta la investigación de Gervais (1994) como la propuesta más clara de triangulación metodológica. Hasta el momento presente, no se ha encontrado ningún trabajo que se haya concentrado en el análisis de imágenes fotográficas como técnica para el estudio de la representación social.

Este estudio se enmarca en una investigación más amplia cuyo objetivo consiste en explorar la representación social sobre los problemas ambientales que es construida y difundida específicamente por la prensa española. Asumiendo que las RS son entidades estables y que requieren tiempo en su proceso de formación, se propone una mirada longitudinal, buscando caracterizar la evolución de esta representación a través de la década de los noventa. El estudio realizado se centra así, en analizar los diferentes temas contenidos en las fotografías de una muestra de artículos de prensa sobre temas medioambientales.

\section{Método}

\section{Muestra}

La muestra se obtiene de un conjunto de noticias publicadas por dos diarios de Barcelona entre el año 1992 y el año 2002. En total, fueron seleccionados 12 ejemplares por año y por diario, escogiendo aquellas noticias relacionados con temas medioambientales en general. La muestra quedó constituida por 800 artículos de prensa. Para el presente estudio se analizaron un total de 266 fotografías, número que se corresponde con el total de fotografías contenidas en la muestra de artículos.

\section{Procedimiento}

Siguiendo los criterios de formato similar (diagramación, secciones, etcétera) y número de lectores, se escogieron los diarios La Vanguardia y El País en su edición barcelonesa. Con el fin de limitar el tamaño de la base de datos, se procedió a revisar un ejemplar de cada diario por mes y por cada año par, siguiendo un sistema de fechas rotativo establecido a priori, en el cual se iban variando los días y semanas de cada mes.

Una vez recogidas las 266 fotografías se procedió a la categorización de los diferentes temas que contenían. Para su categorización no se utilizó un 
sistema de categorías establecido a priori, sino que éste se fue construyendo a partir de la información proporcionada por el propio material analizado (Strauss y Corbin, 1990). A partir del análisis categorial se llevó a cabo un análisis descriptivo.

\section{Resultados}

El primer dato a mencionar es que se observa un incremento en el número de artículos ambientales publicados a lo largo de la década. El número de artículos publicado en cada uno de los diarios en el año 2002 prácticamente supone el doble del número de artículos aparecidos en la muestra correspondiente al año 1992. En datos concretos, se pasó de una media de 3,6 artículos por día (por diario) al principio de la década de los 90 a una media de 6,7 en el 2002.

Más de la mitad de los 800 artículos de la muestra se caracterizan por un estilo de presentación textual y "literaria", sin la presencia de elementos gráficos que acompañen la noticia (59\%). En contraposición, el estilo de presentación "gráfica (sólo o casi)" tiene una mínima presencia (4\%) En este mismo orden, debe subrayarse que la mayoría de los artículos no cuentan con apoyo fotográfico. Los artículos que sí lo hacen (34\%) tienden a incuir una sola fotografía.

En relación con los temas contenidos en las fotografías, como ya se ha indicado, para su categorización no se parte de un sistema de categorías establecido a priori, sino que éste se ha ido construyendo a partir de la información proporcionada por el propio material analizado. En el proceso de categorización progresivo se llegó a 4 grandes categorías, cada una de las cuales ha reunido un número de subcategorías determinado (ver Tabla I).

TABLA I

Categorización de los temas contenidos en las fotografías

\begin{tabular}{ll}
\hline Categorías & Subcategorías \\
\hline Actores Sociales & Políticos \\
& $\begin{array}{l}\text { Expertos ambientales /científicos } \\
\text { Otras personalidades } \\
\text { Otras personas }\end{array}$ \\
\hline Tipo de Paisaje & $\begin{array}{l}\text { Paisaje urbano } \\
\text { Paisaje natural } \\
\text { Paisaje industrial } \\
\text { Paisaje agrícola / ganadero / pesquero }\end{array}$ \\
\hline Afectación del Medio Ambiente & $\begin{array}{l}\text { Zonas afectadas } \\
\text { Personas afectadas } \\
\text { Animales afectados }\end{array}$ \\
\hline Acciones Sociales & Acciones civiles y organizaciones ecologistas \\
\hline Otros & Acciones gubernamentales \\
\hline
\end{tabular}

Como se puede apreciar en la figura 1 , en cuanto a los contenidos temáticos de las referncias fotográficas, destaca la categoría "Tipo de Paisajes" (27.7\%) mientras que un porcentaje similar de fotografías se corresponden con las categorías "Actores Sociales" (21.3\%), registrándose porcentajes menores en las categorías de "Afectación del Medio Ambiente" (19.5\%) y "Acciones sociales" $(17.6 \%)$. 


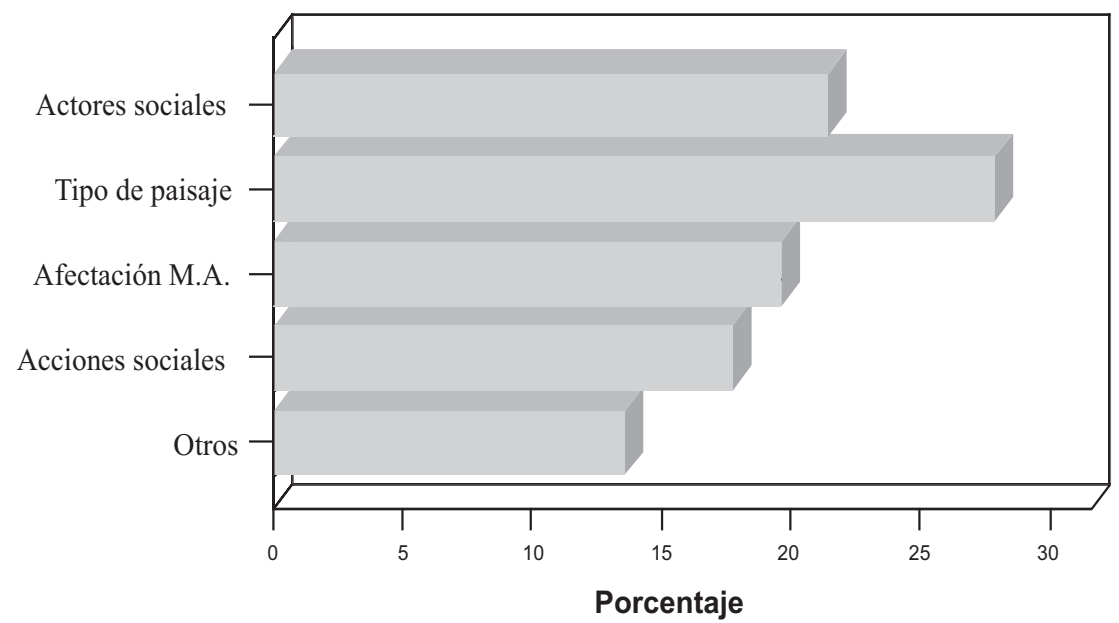

\section{Actores sociales}

Esta categoría recoge las fotografías de personas muy diversas, desde personalidades políticas, expertos u otras figuras conocidas, hasta personas de a pie. En ella se observa claramente la predominancia de las figuras políticas (38\%), seguidas por los expertos ambientales (26\%) y otras personalidades (25\%), con una mínima presencia de otro tipo de personas (11\%) (ver Figura 2).

FIGURA 2

Fotografías de "Actores Sociales"

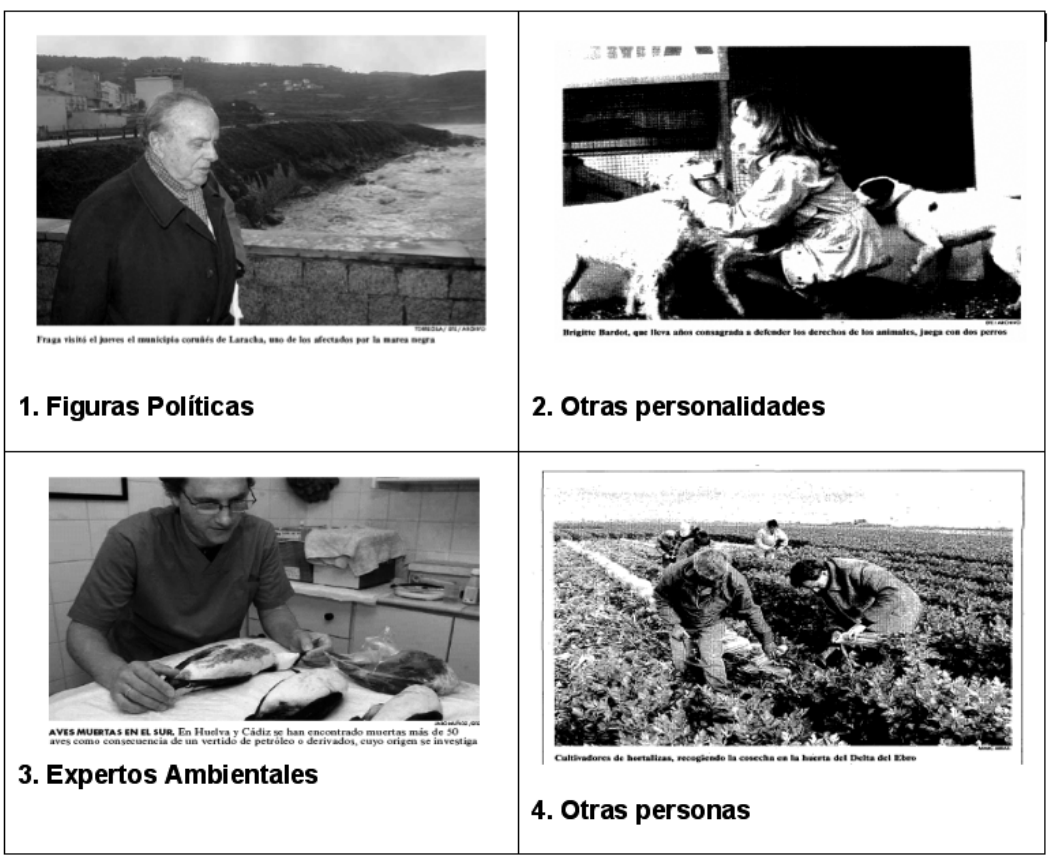


Paisajes

En esta categoría se incluyen fotografías sobre paisajes de entornos tanto naturales como construidos. Se observa una clara predominancia de un tipo particular de paisaje: el paisaje urbano $(57 \%)$, por encima de los paisajes naturales $(19 \%)$, industriales (15\%), agrícolas, ganaderos o pesqueros (9\%) (ver Figura 3).

FIGURA 3

Fotografías de Paisajes

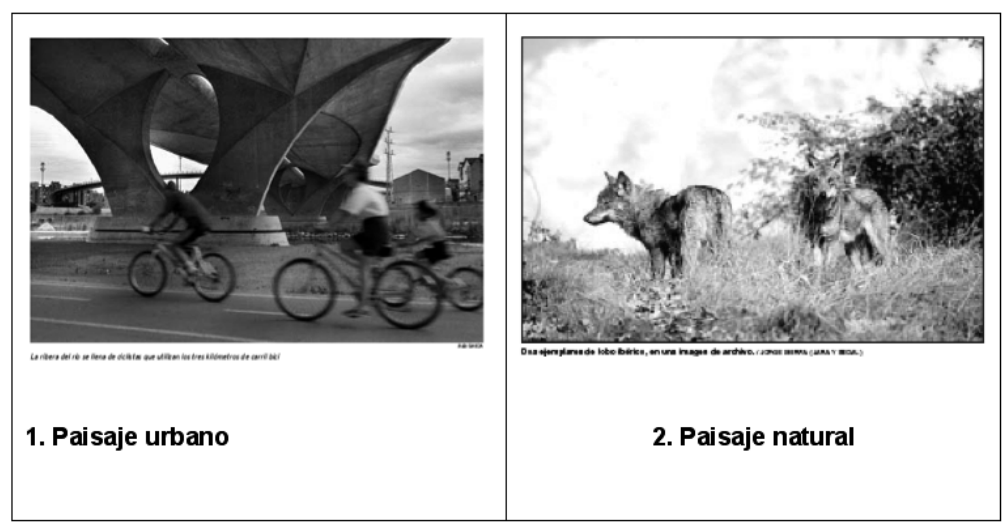

\section{Afectación del medio ambiente}

Esta categoría recoge fotografías que reflejan ecosistemas y seres vivos afectados por problemáticas ambientales específicas como la ocurrencia de accidentes o desastres ambientales. En este sentido, se registra un mayor volumen de fotografías centradas en mostrar los efectos ocasionados en zonas o espacios naturales (70\%) en comparación a las que se centran en mostrar personas o animales afectados. Esto, en cifras, se corresponde con más de dos terceras partes de las fotografías que componen esta categoría (ver Figura 4).

FIGURA 4

Afectación del medio ambiente

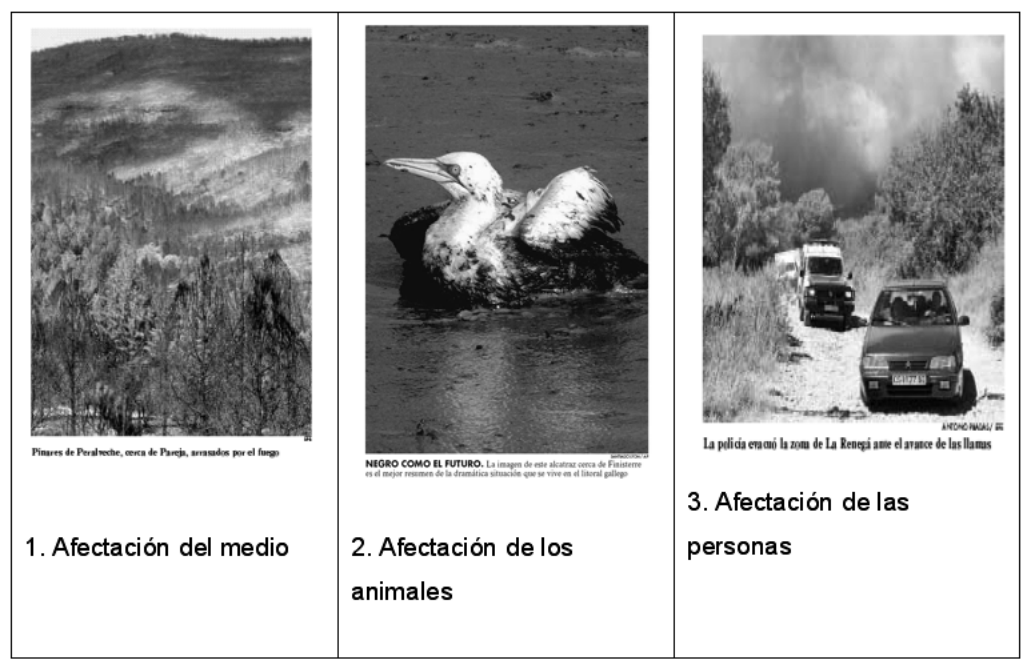




\section{Acciones sociales}

Esta categoría contiene 49 fotografías que reflejan acciones llevadas a cabo por distintos actores sociales, observándose la predominancia de las acciones emprendidas por los ciudadanos y grupos ecologistas (71\%), en comparación con las emprendidas por las diferentes entidades gubernamentales $(29 \%)$.

El primer tipo de acciones concentra en su mayoría movilizaciones, manifestaciones y protestas de distinta magnitud y, por tanto, con distintos grados de impacto social. Son fotografías que se caracterizan por la presencia de un número nutrido de personas llevando carteles o grandes pancartas, alineados recorriendo calles, parados frente a las puertas de algunas entidades ministeriales o en grandes concentraciones en plazas. Algunas de estas fotografías (pocas, en realidad) muestran la participación de activistas de los grupos ecologistas, tan sólo cinco fotografías, todas ellas pertenecientes a las acciones de Greenpeace. También se registraron fotografías que reflejan acciones voluntarias de la gente ante eventos ambientales muy puntuales como socorrer ballenas varadas, o realizar labores de limpieza o recuperación de espacios naturales (ver Figura 5)

FIGURA 5

Acciones sociales

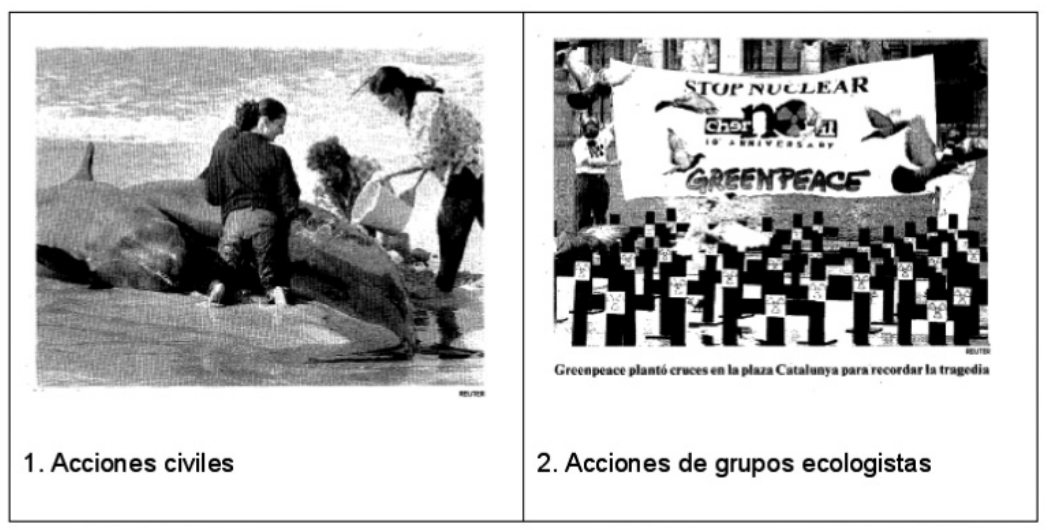

En cuanto a las acciones gubernamentales, se trata de fotografías que reflejan la labor de distintos tipos de técnicos o trabajadores que buscan corregir los efectos ocasionados por algunos eventos ambientales (como por ejemplo, la limpieza de las playas afectadas por derrames petroleros, la extinción de incendios, la recuperación de parajes naturales, etcétera).

\section{Evolución de los temas a lo largo de la década}

Uno de los resultados más relevantes del estudio es el que se deriva del análisis longitudinal y de la evolución a lo largo de la década. En este sentido, se observan diferencias significativas en el tipo de fotografías que predominan en los diferentes años tomando en consideración tanto las categorías generales $\left(X^{2}=\right.$ $44,813 ; d f=20 ; p<.001)$ como las específicas $\left(X^{2}=112,117 ; d f=60 ; p<\right.$ $.000)$. Se realizó un análisis de correspondencias para observar de manera gráfica cómo se distribuyen los temas (ver Figura 6). 
Figura 6

Distribución de los temas de las fotografías de prensa a lo largo de la década de los noventa a través de un análisis de correspondencias

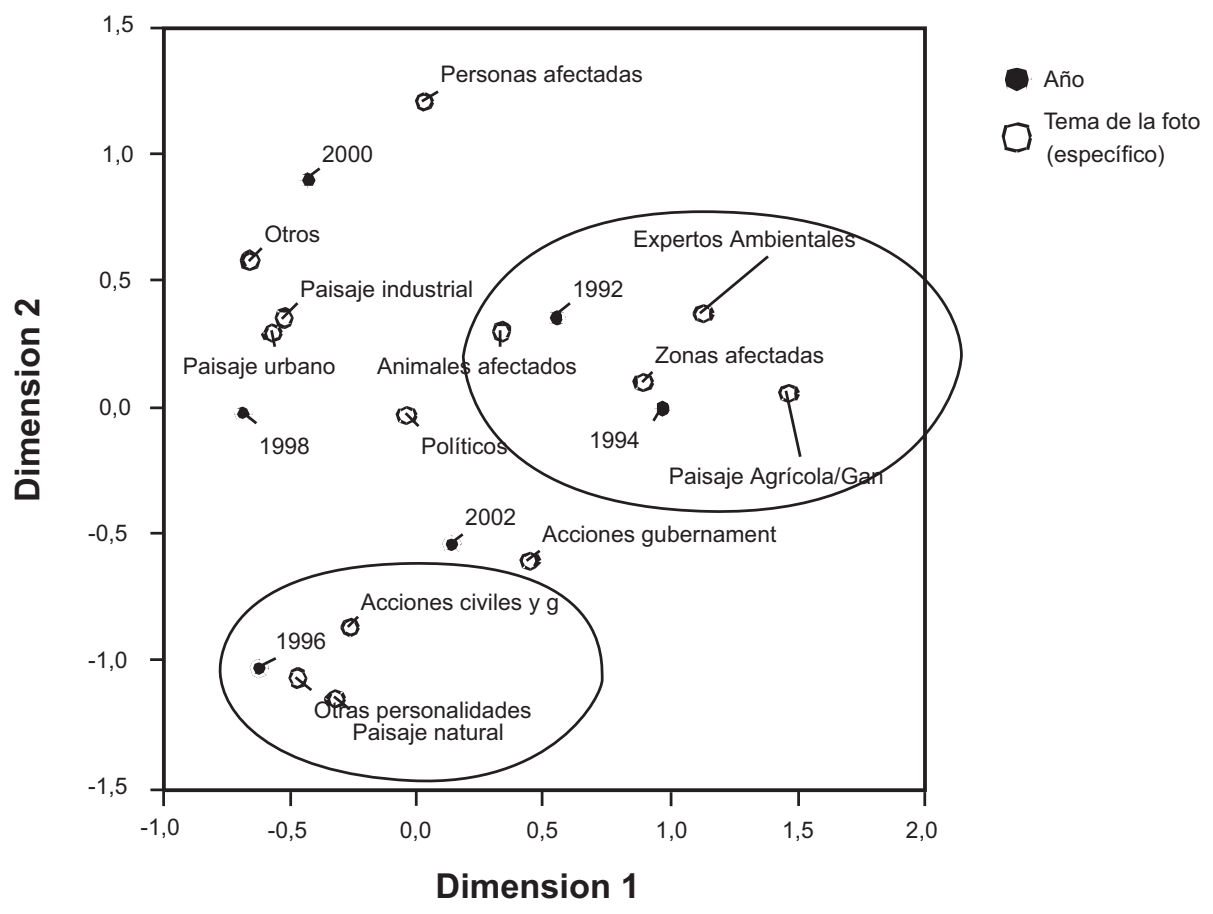

Como se puede observar en esta figura, el principio de la década (años 1992 y 1994, representado por el círculo de la derecha en el gráfico) aglutina fotografías de animales y zonas afectadas, junto con paisajes agrícolas/ganaderos/pesqueros vinculándolas, de entre todos los actores sociales, con los expertos ambientales. A la luz de la Cumbre de Río, como antecedente directo, este hecho podría ser interpretado como una representación anclada en el "discurso científico" en el que los expertos son los que tienen el mayor peso de opinión y expresión sobre las problemáticas ambientales. Por tanto el discurso y la imagen hacen referencia a un lenguaje científico que aún no ha sido asimilado ni convertido en sentido común.

Por otra parte, en el año 1996 predominan fotografías de paisajes naturales, acciones de civiles/grupos ecologistas y otras personalidades. Considerando que esta última categoría recoge principalmente imágenes de actores y figuras públicas que toman la bandera ecologista y profesan públicamente su adscripción, si no al movimiento, sí a determinadas causas conservacionistas, podríamos afirmar que a mediados de la década las fotografías muestran principalmente el "discurso ecologista". La temática medioambiental deja de ser exclusivamente tema de interés y trabajo para los científicos y comienza a estar en el lenguaje cotidiano y expresado por otro tipo de actores sociales.

Por último, observamos que al final de la década (1998) predominan fotografías de paisajes urbanos e industriales vinculados a los actores políticos y, en segundo plano, a las acciones gubernamentales (2002). Todo ello concuerda no sólo con la visión de la politización del medio ambiente que algunos investigadores refieren en sus estudios (Vargas, 2005), sino también con el posible desplazamiento de la RS del medio ambiente de lo natural, como icono, a lo construido. 
Frente a lo natural, lo artificial (paisaje urbano, paisaje industrial) cobra supremacía. Este tipo de entorno es la principal preocupación de los políticos y por tanto, hay una inversión en proyectos urbanísticos y mejora del medio ambiente "natural" del ser humano: la ciudad.

\section{Discusión}

Como ya se ha señalado, entre los resultados más sobresalientes destaca que un tercio del material analizado contenga un apoyo gráfico (al menos una referencia gráfica), siendo el uso de fotografías el apoyo más utilizado. Este dato resulta un tanto paradójico dada la verdadera importancia que tiene el empleo del recurso gráfico, sobre todo a la hora de explicar problemas ambientales globales o de alcance internacional. Un elemento a tener en cuenta, y que debe ser explorado en el futuro, es la comparación de las noticias de medio ambiente y las de otro tipo de temáticas (políticas, internacionales, salud, cultural, deportivas, etcétera) en el uso que unas y otras hacen de elementos gráficos, en general, y de fotografías, en particular.

$\mathrm{Al}$ analizar el contenido de las fotografías destaca la clara predominancia de figuras políticas, seguidas por expertos ambientales entre otras personalidades. Esto puede reflejar la idea de que el medio ambiente es una cuestión política y técnica más que social y popular. También habría que plantearse en que medida la predominancia de figuras políticas no es un reflejo del uso ( $\mathrm{y}$ abuso) que hace el medio (de manera partidaria) de algunas fuentes informativas y/o de la hegemonía de una fuente por encima de las otras.

Además, la utilización mayoritaria de fotografías del paisaje urbano puede estar indicando un cambio en la representación social del ambiente, la cual ha sido históricamente asociada al paisaje natural debido a la vinculación tradicional naturaleza-conservacionismo.

Igualmente, debe destacarse el hecho de que aparezcan fotografías que reflejan ecosistemas y seres vivos afectados por 'problemáticas ambientales' específicas como la ocurrencia de accidentes o desastres ambientales. Predomina la noción del medio ambiente como problema resultante de la acción del ser humano. Por tanto, se comunica la imagen de acción negativa del ser humano sobre la naturaleza, hecho que no aparece en igual dimensión en relación con el entorno urbano -artificializado o tecnológico- que sí está más presente al final de la década.

Por último, se observa un porcentaje menor de fotografías que reflejan acciones emprendidas por diferentes colectivos, observándose la predominancia de las 'acciones' emprendidas por los ciudadanos y grupos ecologistas (movilizaciones, manifestaciones y protestas) en comparación con las emprendidas por las diferentes entidades gubernamentales (actividades de limpieza y recuperación de espacios). Son los agentes sociales civiles, y no la administración pública, los que ejercen mayores acciones de preservación o protección del medio. Indirectamente ello culpabiliza o socava la autoridad moral de las administraciones públicas y los políticos que, por otro lado, son los que más aparecen como personajes.

Para concluir, en el estudio longitudinal se observa no solo que las noticias ambientales se han incrementado a través de la década sino también que se han diversificado en cuanto a la variedad de temas que abarca. En este proceso de diversificación, se observa una gran presencia de problemas urbanos. A pesar de ello, el medio ambiente comienza a ser asociado al entorno urbano y deja de ser asociado al entorno natural. 


\section{Referencias}

Arruda, A. (1998). O ambiente natural e seus habitants no imaginario brasileiro. Negociando a diferenca. En A. Arruda (Org.), Representando a alteridade (pp. 109-128). Petrópolis: Vozes.

BomfiM, Z. \& PoL, E. (2005). Affective dimension in cognitive maps of Barcelona and São Paulo. International Journal of Psychology, 40 (1), 37-48.

CASTRECHINI, A. (1996). Aproximación a la representación del medio ambiente en una comunidad cooperativa. Tesis de maestría. Universidad Simón Bolívar.

CAstrechini, A. \& Pol, E. (2006). Le rôle des médias dans la construction des représentations sociales de l'environnement. En K. Weiss \& D. Marchand (Dir.), Psychologie sociale de l'environnement (pp. 121-132). Rennes: Presses Universitaires de Rennes.

CASTRO, P. (2002). Natureza, ciência e retórica na construçao social da ideia de ambiente. Lisboa: Fundaçao Calouste Gulbenkian.

CASTRO, P. \& LiMA, M. L. (2001). Old and new ideas about the environment and science. Environment and Behavior, 33 (3), 400-423.

GervaIs, M. C. (1994). The theory of social representations: An alternative paradigm for the study of human relationships to the environment. En B. Hernández, E. Suárez \& J. Martínez (Comps.), Interpretación social y gestión del entorno: Aproximaciones desde la Psicología Ambiental (Tomo I; pp. 273-283). Adeje-Tenerife: Universidad de La Laguna.

IвÁŃNEZ, T. (1988). Representaciones sociales. Teoría y método. En T. Ibáñez (Coord.), Ideologías de la Vida Cotidiana (pp. 1390). Barcelona: Sendai.

JODELET, D. (1996). Las representaciones sociales del medio ambiente. En L. Íñiguez \& E. Pol (Comps.), Cognición, representación y apropiación del espacio (pp. 29-44). Monografies Psico-Socio-Ambientals, 9. Barcelona: PUB.

Milgram, S. (1984). Cities as social representations. En S. Moscovici \& R. Farr (Eds.), Social representations (pp. 289-309). Cambridge: Cambridge University Press.

Milgram, S. \& JODELet, D. (1976). Psychological maps of Paris. En H. M. Proshansky, W. H. Ittelson \& L. G. Rivlin (Eds.), Environmental psychology: People and their physical settings (pp. 104-124). Nueva York: Holt, Rinehart and Winston.

MoscovicI, S. (1981). On Social Representations. En J. P. Forgas (Ed.), Social cognition: Perspectives in everyday understanding. Londres: Academic Press.

MoscovicI, S. (1984). The phenomenon of Social Representations. En R. Farr \& S. Moscovici (Ed.), Social Representations (pp. 3-69). Cambridge: Cambridge University Press.

MoscovicI, S. (1993). Introductory Address. Papers on Social Representations, 2 (3) 160-170.

MoscovicI, S. (1997). Social representations theory and social constructionism. Disponible en: http://psyberlink.flogiston.ru/internet/bits/mosc1.htm http://psyberlink.flogiston.ru/internet/bits/mosc1.htm

MoscovicI, S. (2000). Social Representations: Explorations in Social Psycbology. Cambridge: Polity Press.

StRAuss, A. \& CORBIN, J. (1990). Basics of qualitative research: Grounded theory procedures and techniques. Londres: Sage.

VARGAS, G. M. (2005). Naturaleza y medio ambiente: Una visión geográfica. Revista Geográfica Venezolana, 46 (2), 289-304.

WAGNER, W. (1996). The social representation paradigm. Japanese Journal of Experimental Social Psychology, 35, 247-255. 